$1-1-1973$

\title{
Factors influencing the levels of exchangeable potassium in Gilpin and Cookport soils
}

W. B. Barnett

Carl F. Engle

Richard M. Smith

Follow this and additional works at: https://researchrepository.wvu.edu/ wv_agricultural_and_forestry_experiment_station_bulletins

\section{Digital Commons Citation}

Barnett, W. B.; Engle, Carl F.; and Smith, Richard M., "Factors influencing the levels of exchangeable potassium in Gilpin and Cookport soils" (1973). West Virginia Agricultural and Forestry Experiment Station Bulletins. 622T.

https://researchrepository.wvu.edu/wv_agricultural_and_forestry_experiment_station_bulletins/709 @ WVU. It has been accepted for inclusion in West Virginia Agricultural and Forestry Experiment Station Bulletins by an authorized administrator of The Research Repository @WVU. For more information, please contact ian.harmon@mail.wvu.edu. 
Factors Influencing

the Levels of

Exchangeable Potassium in Gilpin and Cookport Soils
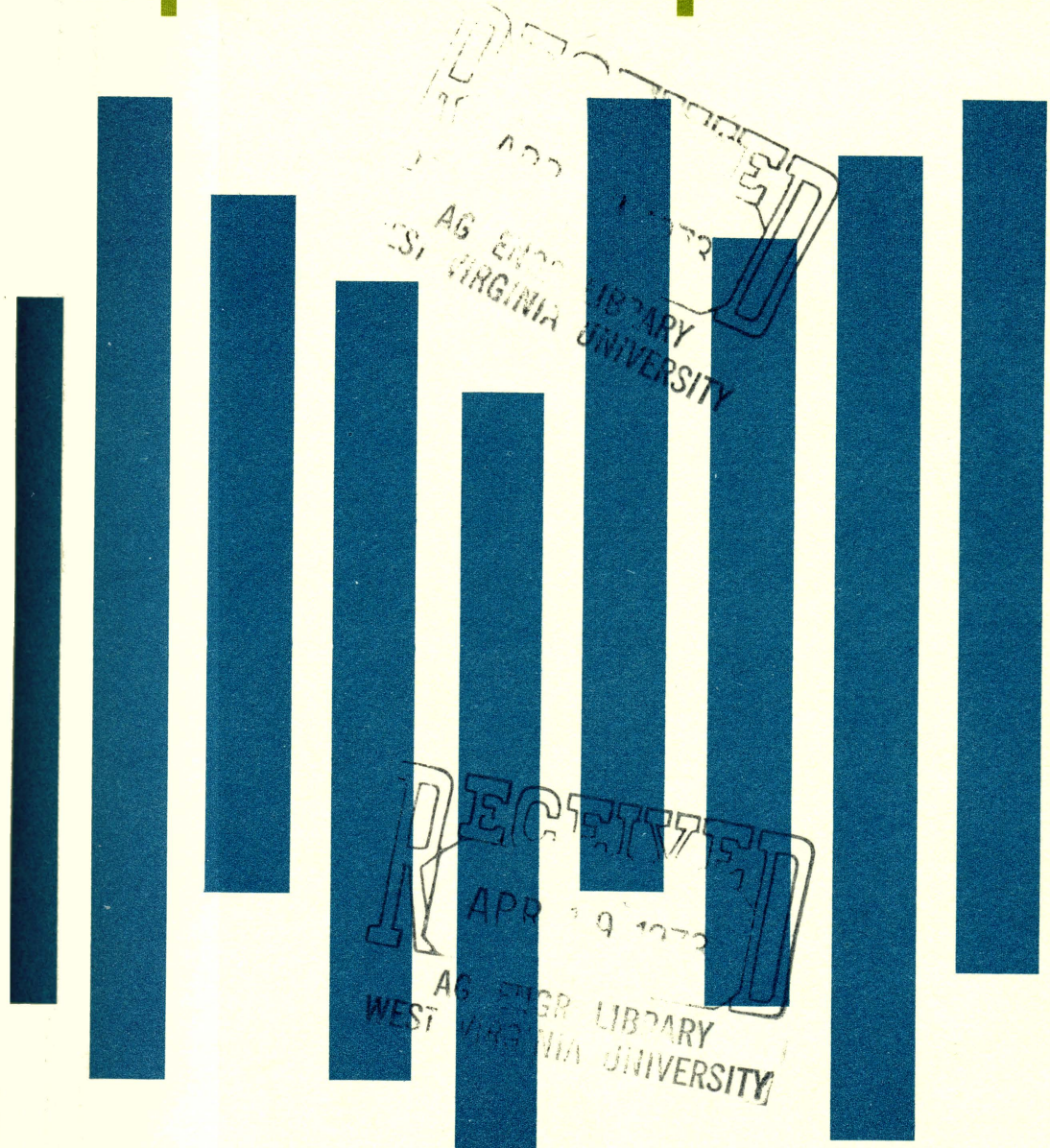

Bulletin 622T

April 1973

West Virginia University Agricultural Experiment Station $5 / 27$ 


\section{[Blank Page in Original Bulletin]}




\section{Factors Influencing}

the Levels of

\section{Exchangeable Potassium}

\section{in Gilpin and Cookport Soils}

W. B. Barrett

C. F. Engle

R. M. Smith

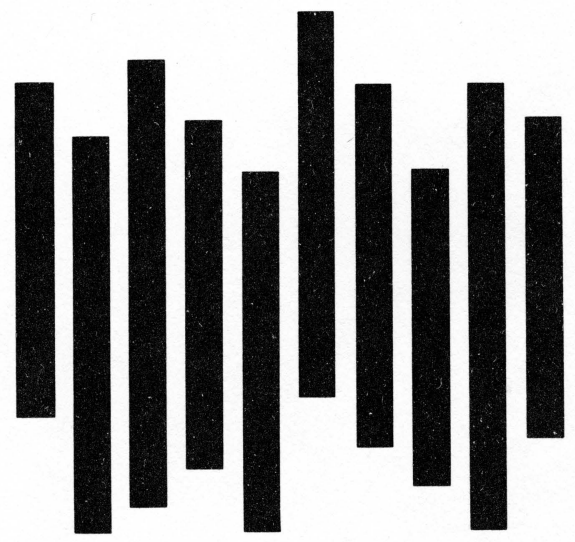

West Virginia University

Agricultural Experiment Station 


\title{
AUTHORS
}

W. B. Barrett was formerly Graduate Assistant in Agronomy; C. F. Engle was formerly Associate Agronomist and State Extension Specialist-Soil Science; and R. M. Smith is Agronomist

\author{
West Virginia University \\ Agricultural Experiment Station \\ College of Agriculture and Forestry \\ R. S. Dunbar, Jr., Director \\ Morgantown
}




\title{
Factors Influencing the Levels of Exchangeable Potassium in Gilpin and Cookport Soils
}

\author{
W. B. Barrett, C. F. Engle, and R. M. Smith
}

P otassium which is available to the plant makes up approximately 1 to 2 per cent of the total potassium in an average mineral soil. Available potassium exists either in the soil solution or is absorbed on the soil colloidal surface where it is in the exchangeable form. Approximately 90 per cent of the available potassium is in the exchangeable form, whereas only 10 per cent exists in the soil solution. Under certain conditions, available potassium becomes "fixed" by certain clay minerals and is not available to the plant. Potassium in this form cannot be removed by ordinary exchange methods and is sometimes referred to as nonexchangeable or fixed potassium. This form does not always remain unavailable to the plant as it may be released slowly from the clay minerals and become available.

Bray and DeTurk (3) found that soils which contain large amounts of fixed potassium may release as much as $288 \mathrm{lbs}$. of potassium per plow layer in Illinois soil during a six-month period. Large changes such as this led to investigations by Childs and Jencks (5). They indicated that levels of exchangeable potassium in the soil may vary widely throughout the year, increasing during the fall, reaching a maximum during winter, and then decreasing during late spring and early summer. They concluded that the seasonal variation was chiefly attributable to fixation and release by clay minerals.

Scott et al. (11) reported that some soils required larger applications of potassium than others before fixation would occur. They observed that high initial levels of exchangeable potassium must be present before consistent fixation takes place, whereas low initial levels of exchangeable potassium were conducive to release of this element.

With soils having high levels of exchangeable potassium, Fine et al. observed initial reduction of exchangeable potassium following freezing. However, soils of moderately low fertility and soils which had received moderate amounts of potassium fertilizers tended toward higher levels of exchangeable potassium after freezing. They found that Miami and Carrington soils, whose clay consists largely of illite, fixed potassium upon freezing and suggested that illite may be the clay mineral responsible for fixation of potassium during freezing.

Montmorillonite, vermiculite, and illite are the clay minerals which appear to be responsible for most of the fixation and release of potassium in soils. Montmorillonite and vermiculite may either fix or release potassium. Numerous workers $(1,2,6,7,10,13)$ have indicated that when montmorillonite is dried, potassium ions become entrapped within the silica sheets. Because of 
the bonding energy between the potassium ions and the silica sheets, the re-expansion of the crystal lattice is prevented. However, Fine et al. (7) and Tisdale and Nelson (13) found that in those clays containing fixed potassium subsequent hydration will result in re-expansion of some but not all layers, resulting in slow release of potassium.

Scott and Smith (12) while working with biotite, observed that fixation and release of potassium could occur simultaneously. Upon drying of biotite some of the silicate layers are forced apart exposing interlayer potassium to exchange and thereby causing potassium to be released. While drying forced some of the layers apart, it also caused a collapse of the clay lattice and fixation of potassium. Only a small number of layers were separated upon drying, but nevertheless this was great enough for potassium to be released. Dowdy and Hutcheson (6) reported that the concentration of approximately .45 milliequivalent of exchangeable potassium per 100 grams of soil may be necessary to fill the interlayer hexagonal oxygen network of expanding lattice minerals sufficiently to prevent distortion of the lattices upon drying, thus preventing additional release of potassium. They concluded that drying resulted in potassium fixation when the exchangeable potassium was .45 milliequivalent per 100 grams or greater, whereas potassium was released when the level was below this.

Burns and Barber (4) suggested that a certain temperature must be reached before a measurable amount of nonexchangeable potassium is released from moist soil. Potassium in the nonexchangeable form has an activation energy which must be acquired before it can break the bond holding it in position and move to the site where it becomes exchangeable. Some soils exhibited an increase in exchangeable potassium at a low temperature indicating that the energy level which the nonexchangeable potassium must acquire to break its bonds is lower in some soils than in others.

The purpose of this study was to determine the magnitude of exchange. able potassium variation throughout the year in two surface soils, and to gain some understanding of the mechanisms responsible for the measured variations.

\section{Experimental Methods and Materials}

The soils used in the study were selected from the Gilpin and Cookport series. The Gilpin is a moderately deep, well-drained, strongly acid soil developed on interbedded acid gray sandstone, siltstone, and shale. Its classification is Typic Hapludults; fine-loamy, mixed, mesic. Modal Cookport is a moderately deep and moderately well-drained soil that developed on uplands in acid, gray material weathered from sandstone and shale: classified, Aquic Fraquidults; fine-loamy, mixed, mesic. The Cookport in this study was a shallow (or lithic) variant with bedrock sandstone at a depth of 20 inches.

Three locations were involved in this study. The Cookport soil was on a 0 to 3 per cent slope and had a cover of grasses with orchard grass as the dominant species. The $\mathrm{pH}$ of the soil ranged from 5.3 to 5.6 at a depth of 0 
1012 inches. The Gilpin soil had a cover of mixed pasture species and was also acid in reaction with a range in $\mathrm{pH}$ of 5.1 to 5.4 at a depth of 0 to 12 inches. There were two locations on this soil; one on a north facing slope of 30 to 35 per cent and the other on a south facing slope also of 30 to 35 per cent.

Soil samples were collected at each location and analyzed for exchangeable potassium and other properties. Samples were collected to a depth of 12 inches every two to four weeks over a nine-month period, December, 1967 to september, 1968.

Soil moisture samples were collected in the same area, in the same manner, and on the same date as samples used for exchangeable potassium.

Soil samples for clay mineral identification were processed according to Kunze and Rich (9).

\section{Laboratory Freezing and Thawing Determinations}

During October, 1967, soil samples were collected from each of the three locations at a depth of 0 to 3 inches. The samples were air-dried and passed through a 20 -mesh screen. For each of the three locations 42 samples, each weighing 10 grams, were wetted to 30 per cent moisture and placed in air-tight, $50-\mathrm{ml}$ centrifuge tubes. The samples were stored at this moisture content for three weeks before placing in a freezer at $18^{\circ} \mathrm{F}$. Two of the frozen soil samples were removed from the freezer daily for a period of ten days and analyzed for exchangeable potassium. The samples remaining in the freezer at the end of the ten days were then subjected to two to twelve freezing and thawing cycles, each cycle requiring 24 hours. The samples were analyzed for exchangeable potassium immediately after final thawing.

\section{Laboratory Wetting and Drying Determinations}

During October, 1967, soil samples were collected from each of the three locations at a depth of 0 to 3 inches. The samples were air-dried and passed through a 20-mesh screen. Twenty-two, 10-gram samples were wetted to different moisture levels and stored for 21 days in air-tight, 50-ml centrifuge tubes. Duplicate samples used in this experiment were at levels of $0,10,20$, $30,40,50,60,70,80,90$, and 100 per cent moisture. At the end of the 21 days the samples were analyzed for exchangeable potassium.

In another experiment, twenty, 10-gram samples were wetted to 30 per cent moisture and placed in air-tight, 50-ml centrifuge tubes. After 24 hours, duplicate samples were removed daily from the experiment for a period of ten days and analyzed for exchangeable potassium.

\section{Results and Discussion}

Levels of exchangeable potassium occurring in the Gilpin and Cookport soils varied considerably with time of sampling (Figures 1, 2, and 3). Exchangeable potassium generally was higher during the winter and early 
spring, and then decreased during the summer at each location. This was particularly evident with the Gilpin soil on a south facing slope (Figure 3).

The Cookport soil was located in an area on which a barn had stood and it seems likely that decomposed manure resulted in a high level of organic matter (6.4 per cent) as well as the high level of exchangeable potassium. The Gilpin soil on both the north and south exposures contained a high level of organic matter at 0 to 3 inches depth (5.2, 5.0 per cent respectively) and a high level of exchangeable potassium. This is not unrealistic since both locations had been in permanent sod for a long period of time.

Figures 1, 2, and 3 show the relationship of exchangeable potassium to time and moisture content. Moisture content on the north slope is highly correlated with exchangeable potassium, whereas at the other two locations moisture content is not significantly correlated with exchangeable potassium. This does not necessarily mean that moisture had a greater effect on the north slope than on the south slope or at the Agronomy farm in Morgantown. It is possible that moisture had a real influence on potassium release and fixation without being correlated signficantly with exchangeable potassium. The moisture content at the time of sampling may not always have reflected the influence of moisture on the level of exchangeable potassium in the soil because of the time lapse between wetting, sampling and potassium release.

Laboratory studies conducted on soils at each location indicated that the level of exchangeable potassium in the soil was affected by moisture content and time. Figures 4, 5, and 6 show the effect of wetting and drying on release and fixation of potassium at each location. Samples which had been stored for 21 days at different moisture contents showed essentially no change in ppm $\mathrm{K}$ until the 10 per cent moisture level was reached. At this point, the potassium level dropped abruptly approaching that of air-dry samples. This drop suggests that the fixation of potassium did not start to occur for these soils until the samples were below 20 per cent moisture. Table 1 shows the levels of exchangeable potassium at each moisture level. It is evident that each location follows a general trend where fixation does not start to occur until below 20 per cent moisture. The Gilpin and Cookport soils fixed approximately 60 and 100 ppm potassium, respectively, below 20 per cent moisture. These are large values, but according to Jencks (8), the Cookport and Gilpin soils that he studied had potassium fixing capacities of 1,022 lb./A and 1,207 lb./A, respectively.

Air-dried soil samples from each location which were wetted to $30 \mathrm{per}$ cent moisture released potassium at increasing rates over a ten-day period. The level of ppm $\mathrm{K}$ released at the end of that period was nearly equal to the value reached for a sample held at 30 per cent moisture for 21 days. Table 2 shows the daily levels of exchangeable potassium for a ten-day period following wetting to 30 per cent moisture. By extrapolation of the curves it appears that exchangeable potassium would have increased until a constant value was reached somewhere between 14 to 21 days.

Insufficient evidence was obtained in this study to indicate what minerals are fixing potassium. However, vermiculite and montmorillonite could be of 


\section{FIGURE 1}

The Effect of Time and Depth of Sampling on Exchangeable

Potassium and Moisture Content in Cookport Soil

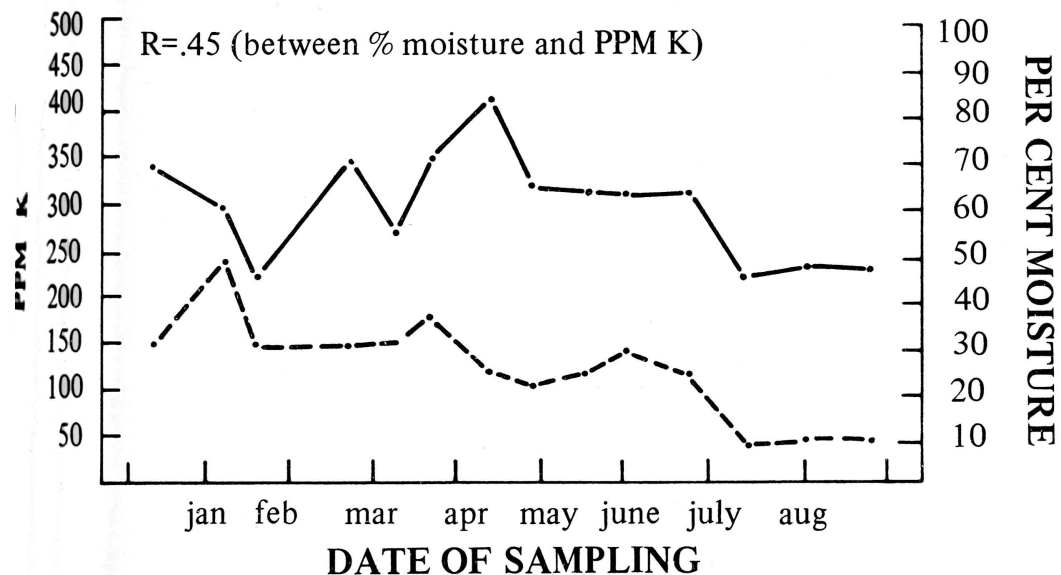

PPM K 0-12"

$\%$ MOISTURE 0-12"

\section{FIGURE 2}

The Effect of Time and Depth of Sampling on Exchangeable

Potassium and Moisture Content in Gilpin Soil, North Slope

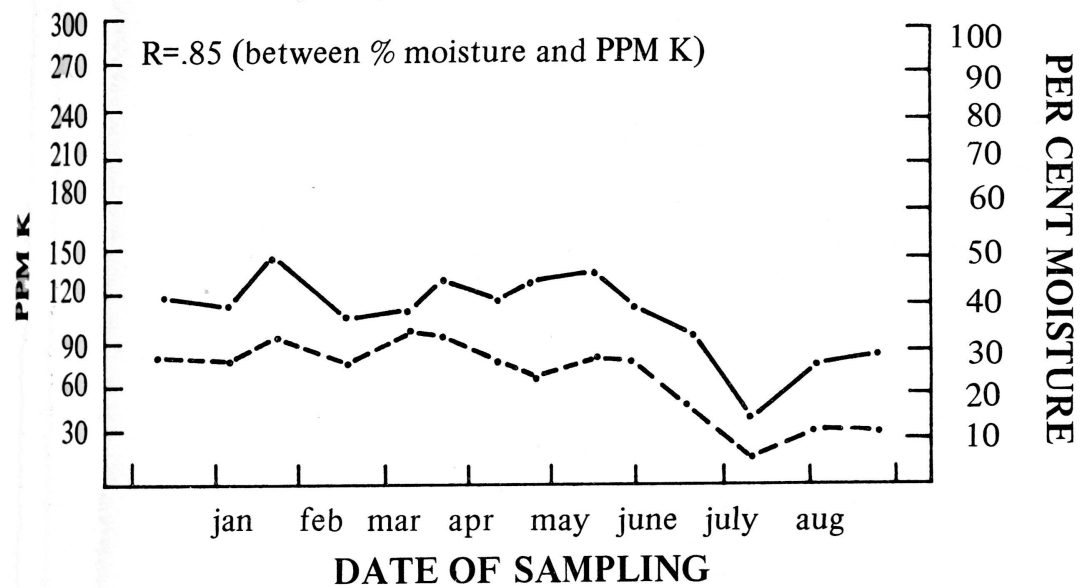
PPM K 0-12"

$\%$ MOISTURE $0-12 "$ 
FIGURE 3

The Effect of Time and Depth of Sampling on Exchangeable Potassium and Moisture Content in Gilpin Soil, South Slope

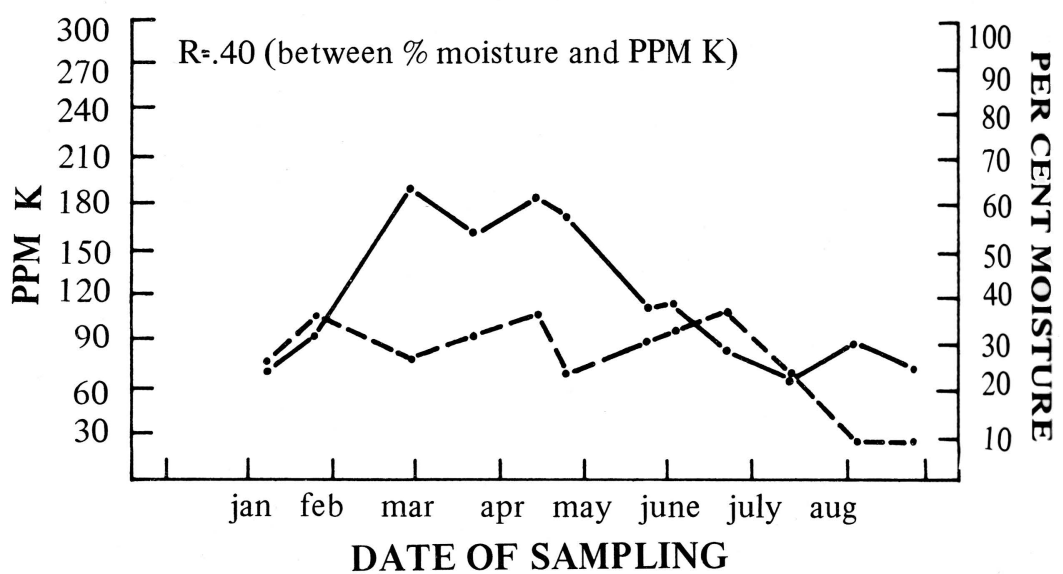
PPM K 0-12"

\% MOISTURE $0-12 "$

FIGURE 4

The Effect of Laboratory Wetting and Drying on

Exchangeable Potassium in Cookport Soil

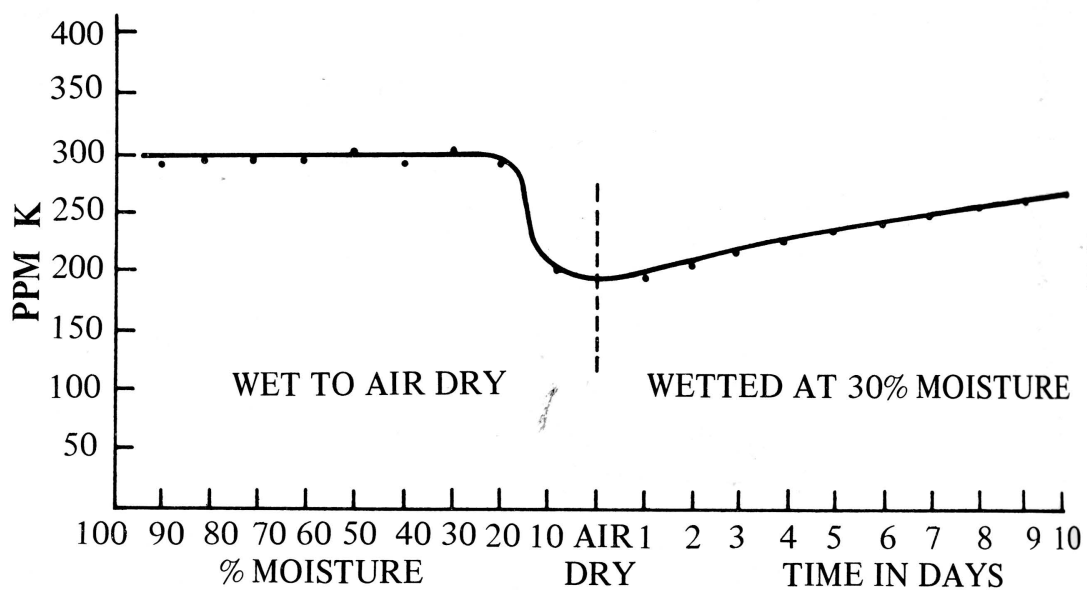




\section{FIGURE 5}

The Effect of Laboratory Wetting and Drying on

Exchangeable Potassium in Gilpin Soil, North Slope

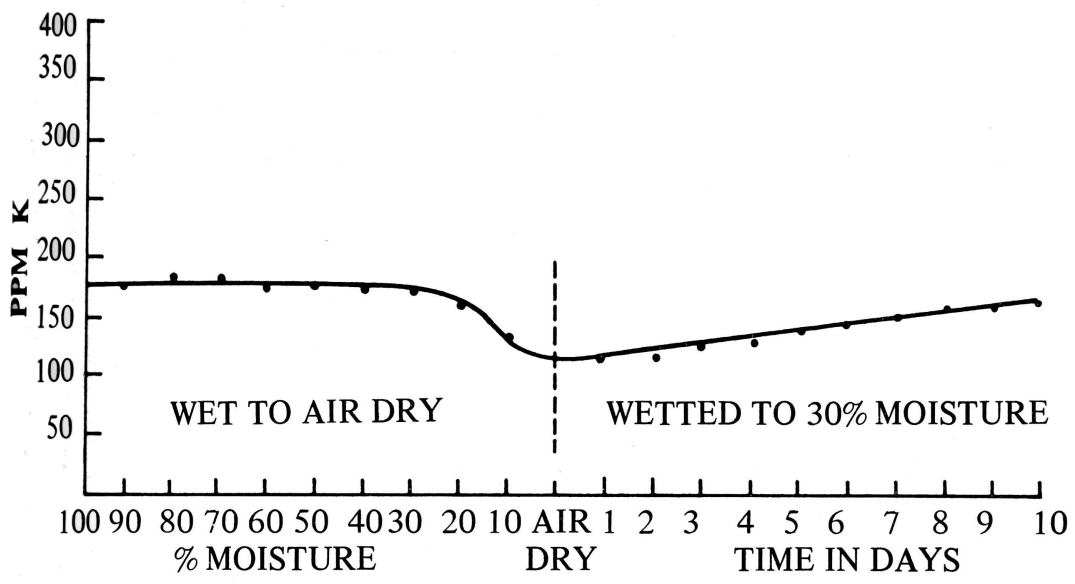

\section{FIGURE 6}

The Effect of Laboratory Wetting and Drying on Exchangeable Potassium in Gilpin Soil, South Slope

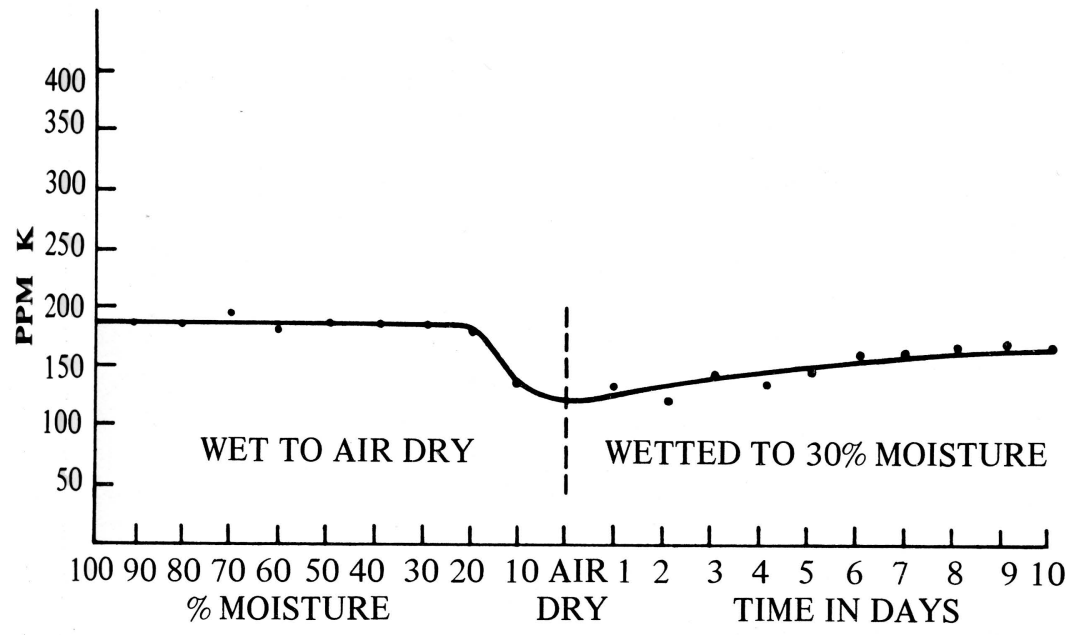




\section{TABLE 1}

The Effect of Laboratory Moisture Level on Exchangeable Potassium over a 21-Day Period in Gilpin and Cookport Soils

\begin{tabular}{cccc}
\hline & \multicolumn{3}{c}{ Location } \\
\cline { 2 - 4 } Per Cent & $\begin{array}{c}\text { North Slope } \\
\text { Gilpin }\end{array}$ & $\begin{array}{c}\text { South Slope } \\
\text { Gilpin }\end{array}$ & $\begin{array}{c}\text { Agronomy Farm (Level) } \\
\text { Cookport }\end{array}$ \\
\hline & ppm & ppm & ppm \\
100 & 179 & 190 & 298 \\
90 & 180 & 191 & 292 \\
80 & 182 & 190 & 297 \\
70 & 183 & 193 & 297 \\
60 & 180 & 189 & 298 \\
50 & 181 & 190 & 300 \\
40 & 180 & 190 & 296 \\
30 & 179 & 190 & 300 \\
20 & 166 & 185 & 294 \\
10 & 130 & 137 & 205 \\
Air Dry & 111 & 120 & 195 \\
\hline
\end{tabular}

TABLE 2

The Effect of Time and Constant Moisture* on Exchangeable Potassium in Gilpin and Cookport Soils

\begin{tabular}{cccc}
\hline \multirow{2}{*}{$\begin{array}{c}\text { Number } \\
\text { of } \\
\text { Days }\end{array}$} & $\begin{array}{c}\text { North Slope } \\
\text { Gilpin }\end{array}$ & $\begin{array}{c}\text { South Slope } \\
\text { Gilpin }\end{array}$ & $\begin{array}{c}\text { Agronomy Farm (Level) } \\
\text { Cookport }\end{array}$ \\
\cline { 2 - 4 } & ppm & ppm & ppm \\
1 & 118 & 127 & 200 \\
2 & 123 & 130 & 210 \\
3 & 130 & 140 & 221 \\
4 & 137 & 135 & 232 \\
5 & 140 & 142 & 241 \\
6 & 145 & 149 & 245 \\
7 & 150 & 153 & 250 \\
8 & 154 & 159 & 257 \\
9 & 160 & 160 & 260 \\
10 & 163 & 162 & 264 \\
\hline
\end{tabular}

*Samples were kept at constant $\mathbf{3 0}$ per cent moisture throughout the experiment. 
major importance since they are generally accepted as potassium fixers. Table 3 indicates that with the Cookport soil illite, vermiculite, and montmorillonite, either singly or more likely collectively, were responsible for potassium fixation and release. With the Gilpin soil illite and montmorillonite would be suspected of fixation and release on the north slope and illite primarily on the south slope. Lattice distortion in illite upon drying and wetting would be expected to result in both fixation and release (12).

The large changes in levels of potassium which occur between sampling dates (as shown in Figures 1 through 3 ) may be attributed partially to fixation and release of potassium by wetting and drying. During the summer months, decrease in exchangeable potassium could be caused by crop uptake, and by fixation as the soils dried in July and August after earlier release aused by soil wetting.

Previous investigations $(2,6,7,10,13)$ have yielded evidence that drying causes the clay lattice to collapse and fix potassium. Release of potassium on drying is associated with moderately low levels of potassium (6). It may be that the levels of potassium were low enough for some to be released by drying on the south slope for the August sampling date as shown in Figure 3.

Both fixation and release of potassium could occur simultaneously in the ame soil system when the commonly occurring mixtures of illite and expanding lattice clays are present. Further, it is not inconceivable for fixation and release to occur simultaneously within the framework of one interstratified clay mineral lattice. Fixation and release are reversible reactions depending upon existing conditions in the active soil environment.

Figures 7,8 , and 9 show the effect of freezing and thawing on exchangeable potassium in samples from each location. Freezing continuously at $18^{\circ} \mathrm{F}$ fixed nearly $85 \mathrm{ppm} \mathrm{K}$ in the Cookport soil. In the Gilpin soil, however, freezing had no effect on the level of $\mathrm{K}$ over a ten-day period. Results showing the effect of freezing on exchangeable potassium for the Gilpin and Cookport soils are presented in Table 4. According to previous investigations by Fine et al. (7), illite has been found to fix potassium upon freezing. It may be the clay mineral responsible for fixation in the Cookport soil.

Freezing and thawing released potassium from Gilpin and Cookport soils as shown in Figures 7, 8, 9 and Table 5. At each location, potassium release by freezing and thawing was greater than that which occurred by wetting indicating the disruptive effect of freezing and thawing on the clay mineral lattice.

Figures 1 through 3 show large changes which occur in exchangeable potassium during the winter months. Laboratory results indicate that decreases in exchangeable potassium in surface soil during the winter months may be caused by fixation due to freezing, and increases due to release by freezing and thawing.

Even though the Gilpin and Cookport soils behave similarly upon wetting and drying and freezing and thawing, the quantities of potassium that were fixed or released were much higher on the Cookport soil. As shown in Figures 
1 through 3 , there is much more fluctuation between sampling dates on the Cookport soil than on the Gilpin soil. Large changes which occur between sampling dates at any depth may be partially attributed to the high levels of potassium in the soil. In seems imperative that soils like the Cookport which alternately fix and release considerable potassium and are being maintained at a high available level be sampled for testing under standardized conditions of soil moisture, season and plant growth.

\section{TABLE 3}

Relative Abundance of Clay Minerals in the Soils

\begin{tabular}{lcccc}
\hline & \multicolumn{4}{c}{ Relative Clay Mineral Abundance } \\
\cline { 2 - 5 } Soil & Illite & Vermiculite & Montmorillonite & Kaolinite \\
\hline Cookport & Medium & high & high & high \\
Gilpin, north slope & Medium & low & medium & medium \\
Gilpin, south slope & Medium & low & low & medium \\
\hline
\end{tabular}

\section{FIGURE 7}

The Effect of Laboratory Freezing and Thawing on Exchangeable Potassium in Cookport Soil

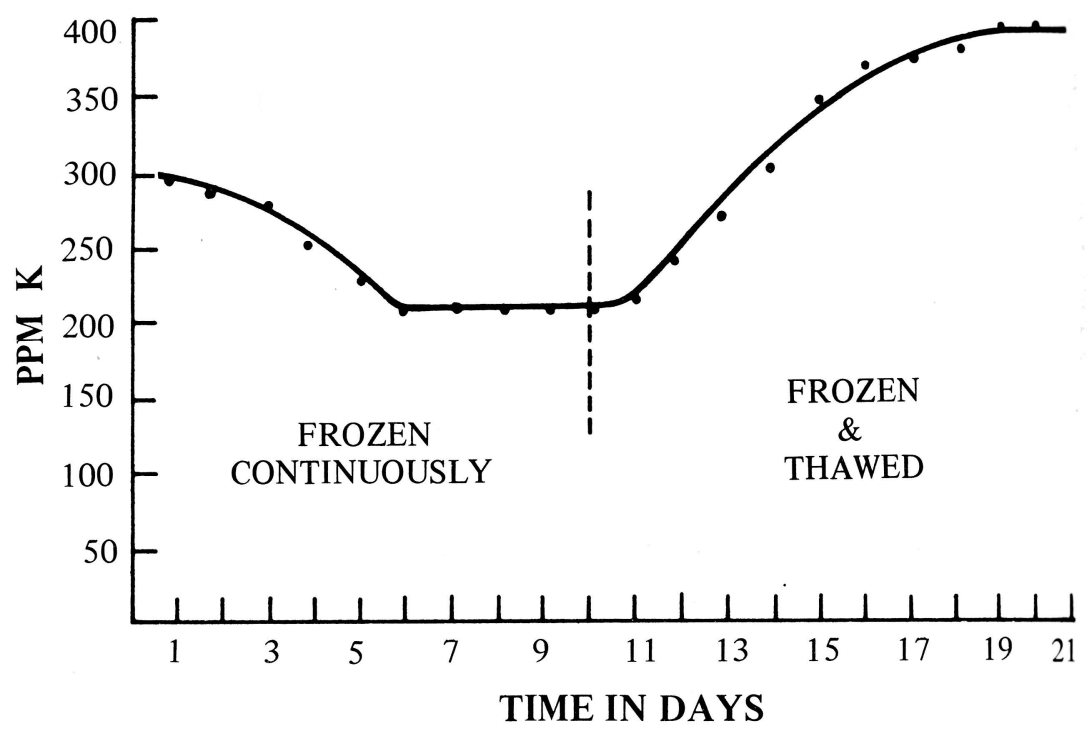




\section{FIGURE 8}

The Effect of Time and Depth of Sampling on Exchangeable

Potassium and Moisture Content in Gilpin Soil, North Slope

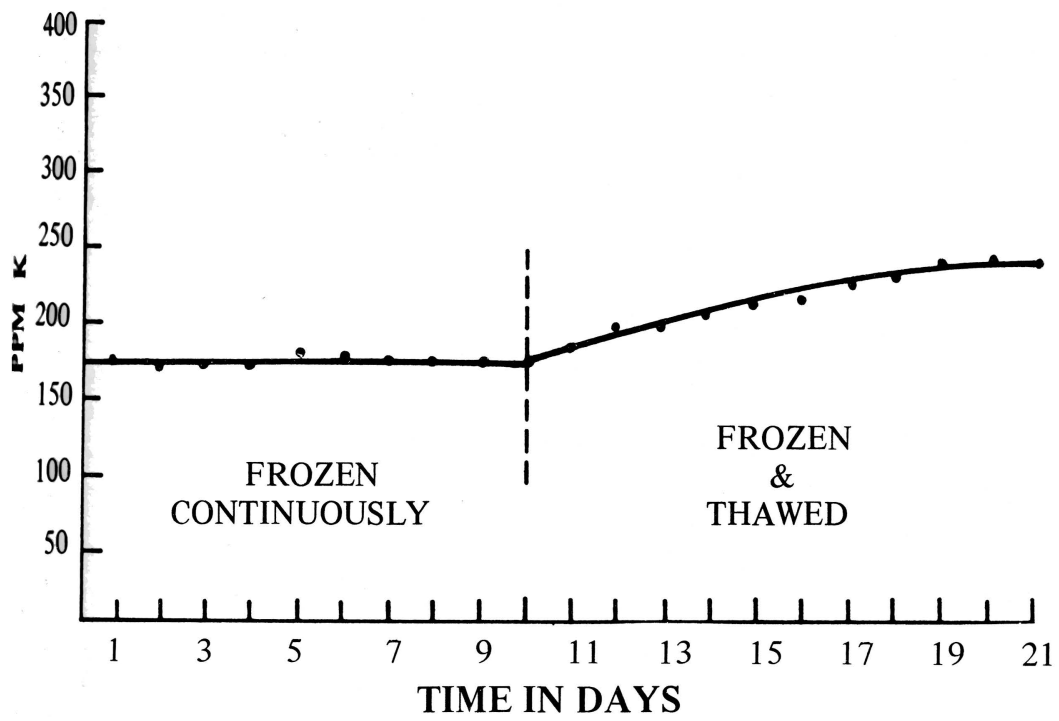

FIGURE 9

The Effect of Laboratory Freezing and Thawing on Exchangeable Potassium in Gilpin Soil, South Slope

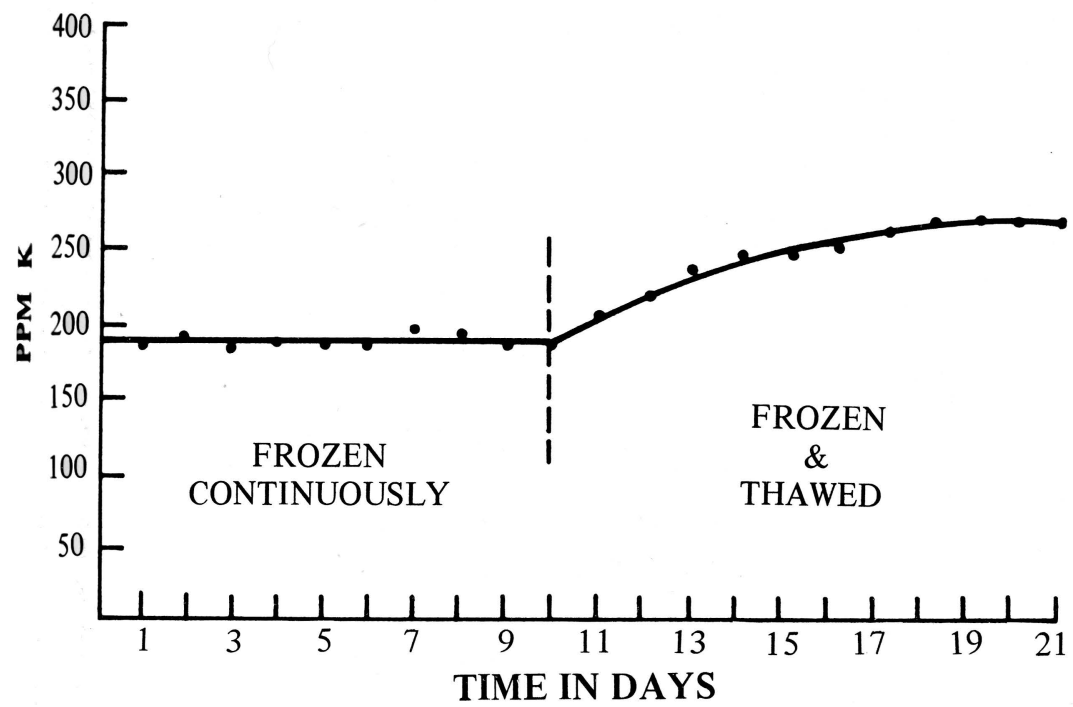




\section{TABLE 4}

The Effect of Time and Continuous Freezing at $18^{\circ} \mathrm{F}$ on

Exchangeable Potassium in Gilpin and Cookport Soils

\begin{tabular}{cccc}
\hline $\begin{array}{c}\text { Number } \\
\text { of } \\
\text { Days }\end{array}$ & $\begin{array}{c}\text { North Slope } \\
\text { Gilpin }\end{array}$ & $\begin{array}{c}\text { South Slope } \\
\text { Gilpin }\end{array}$ & $\begin{array}{c}\text { Agronomy Farm (Level) } \\
\text { Cookport }\end{array}$ \\
\cline { 2 - 4 } & ppm & ppm & ppm \\
1 & 175 & 185 & 295 \\
2 & 173 & 187 & 290 \\
3 & 175 & 185 & 280 \\
4 & 174 & 186 & 255 \\
5 & 177 & 185 & 231 \\
6 & 176 & 185 & 210 \\
7 & 175 & 189 & 212 \\
8 & 175 & 187 & 211 \\
9 & 175 & 185 & 210 \\
10 & 174 & 185 & 210 \\
\hline
\end{tabular}

\section{TABLE 5}

The Effect of Laboratory Freezing and Thawing on Exchangeable Potassium in Gilpin and Cookport Soils

Number of Freezing Cycles* North Slope Gilpin

Location

\begin{tabular}{rrrr}
\hline & ppm & ppm & ppm \\
2 & 185 & 207 & 220 \\
3 & 195 & 220 & 250 \\
4 & 230 & 230 & 276 \\
5 & 210 & 240 & 313 \\
6 & 213 & 248 & 340 \\
7 & 220 & 253 & 364 \\
8 & 225 & 260 & 380 \\
9 & 230 & 264 & 386 \\
10 & 234 & 270 & 400 \\
11 & 240 & 270 & 401 \\
12 & 241 & 270 & 400
\end{tabular}

* One freezing cycle equals 12 hours of freezing at $18^{\circ} \mathrm{F}$ and 12 hours of thawing at room temperature. 


\section{Summary}

Levels of exchangeable potassium in Gilpin and Cookport soils varied with the time and soil moisture. The levels were higher during winter and spring and lower during the summer.

The levels fluctuated much more between sampling dates in the Cookport soil than in the two sites of the Gilpin soil. The difference may be attributed to high levels of exchangeable potassium in the Cookport as well as to differences in clay mineral types and concentrations.

The clay minerals and the level of exchangeable potassium appeared to be of major importance in controlling the quantity of potassium that was fixed or released. According to laboratory results, large decreases in exchangeable potassium during the winter may be attributed to fixation by continuous freezing. Illite is known to fix potassium on freezing when very high levels of potassium exist in the soil, and it could be that this is the mineral responsible. Large increases during the winter may be caused by freezing and thawing which could bring about the release of potassium through its disruptive action on the clay mineral lattice.

Laboratory studies also indicate that drying may have contributed to the large decreases in exchangeable potassium during the summer.

Montmorillonite, vermiculite, and illite might be responsible here since they are known fixers upon drying when there are high levels of potassium in the soil. However, at lower levels, it is common for illite to release potassium on drying.

Increases and decreases in exchangeable potassium could largely be attributed to freezing and thawing, wetting and drying, and plant use. The differences in the quantities of potassium that were fixed or released between the Cookport and Gilpin soils appear to be due to the differences in levels of exchangeable potassium, and type or concentration of clay minerals at each location.

Correlations between exchangeable potassium and field moisture content indicate that moisture had an effect on the level of exchangeable potassium in the soil. However, the relationship was not close enough to be considered quantitatively useful. Obviously, moisture content at the time of sampling does not indicate how long the soil has been at a particular moisture level which was shown to influence quantities of exchangeable potassium. 


\section{Bibliography}

(1) Attoe, O. J. 1947. Potassium fixation and release in soils occurring under moist and drying conditions. Soil Sci. Soc. Amer. Proc. 11:145.

(2) Bates, T. E., and A. D. Scott. 1964. Changes in exchangeable potassium observed on drying soils after treatment with organic compounds: I. Release. Soil Sci. Soc. Amer. Proc. 28:769-772.

(3) Bray, R. H., and E. E. DeTurk. 1939. The release of potassium from nonreplaceable forms in Illinois soils. Soil Sci. Soc. Amer. Proc. 3:101-106.

(4) Burns, A. F., and S. A. Barber. 1961. The effect of temperature and moisture on exchangeable potassium. Soil Sci. Soc. Amer. Proc. 25:349.

(5) Childs, F. D., and E. M. Jencks. 1967. Effect of time and depth of sampling upon soil test results. Agron. J. 59:537-540.

(6) Dowdy, R. M., and T. B. Hutcheson. 1963. Effect of exchangeable potassium levels and drying on release and fixation of potassium by soils as related to clay mineralogy. Soil. Sci. Soc. Amer. Proc. 27:31-34.

(7) Fine, L. O., T. A. Bailey, and E. Truog. 1940. Availability of fixed potassium as influenced by freezing and thawing. Soil Sci. Soc. Amer. Proc. 5:183-186.

(8) Jencks, E. M. 1968. Relationship between exchangeable and boiling nitric acid-extractable potassium in seventy-five West Virginia Soil Series. Agron. J. 60:636-639.

(9) Kunze, G.W., and C.I. Rich. 1959. In Southern Cooperative Series Bulletin 61, p. 144.

(10) Malquori, A., and L. Wiklander. 1950. Influence of alternate wetting and drying on potassium and magnesium fixation and base exchange capacity of synthetic aluminum and iron silicates. Int. Congr. of Soil Sci. 1:141-146.

(11) Scott, A. D., J. J. Manway, and E. M. Stickney. 1957. Soil potassium moisture relations: Potassium release observed on drying Iowa soil with added salts on $\mathrm{HCl}$. Soil Sci. Soc. Amer. Proc. 32:493-501.

(12) Scott, A. D., and S. J. Smith. 1968. Mechanism for soil potassium release by drying. Soil Sci. Soc. Amer. Proc. 32:443-444.

(13) Tisdale, S. L., and W. L. Nelson. 1966. Soil Fertility and Fertilizers. The Macmillan Co., New York. 


\section{[Blank Page in Original Bulletin]}


[Blank Page in Original Bulletin] 